\title{
A Turn-On Fluorescent Probe for Detecting Nitric Oxide in Aqueous Media
}

\author{
Eunhae Koo and Jong-Chul Lee \\ Advanced Materials Convergence Division, Korea Institute of Ceramic Engineering and Technology, Seoul, Republic of Korea \\ Correspondence should be addressed to Eunhae Koo; ehkoo@kicet.re.kr
}

Received 24 September 2014; Accepted 4 December 2014; Published 25 December 2014

Academic Editor: Jung Y. Huang

Copyright (C) 2014 E. Koo and J.-C. Lee. This is an open access article distributed under the Creative Commons Attribution License, which permits unrestricted use, distribution, and reproduction in any medium, provided the original work is properly cited.

\begin{abstract}
Imaging of nitric oxide (NO) in living cells can provide new insights in understanding unsolved pathways in the cardiovascular and neurological dysfunction and many types of cancers. For the detection of NO under physiological conditions, we synthesized a turn-on fluorescent probe comprising CdSe/ZnS quantum dots (QDs) coordinated with dirhodium complex. Emission from $\mathrm{CdSe} / \mathrm{ZnS}$-QDs is quenched when coordinated with the dirhodium complex but can be restored upon the displacement by nitric oxide.
\end{abstract}

Since nitric oxide (NO) was described as an endothelium-derived relaxing factor in 1987 [1, 2], it has been well established that $\mathrm{NO}$ is a ubiquitous messenger molecule in the cardiovascular, nervous, and immune systems and tumor progression [3-5]. In addition, NO is known as a double edged sword in many diseases, especially cancer, because of its roles of an uncharged free radical as well as a radical scavenger [6]. The exact function is depending on its temporal and spatial distribution in the body. However, NO is highly reactive and it can be converted to other species quickly; thus it is very difficult to detect and monitor the concentration of NO in vivo. Fluorescence-based approach has been shown in meeting the requirement to monitor $\mathrm{NO}$ molecule directly in the biological systems [7-11]. Also, Rhodamine-based fluorescent probes for detecting ions have been of interest in living cell imaging [12-14]. Herein, we describe new QDsbased nanohybrids incorporated with transition metal complexes that sense NO by turn-on emission with nanomolar sensitivity in aqueous media.

Nagano and Yoshimura developed NO probes containing organic fluorophores, in which the fluorescence of the organic probe was turn-on upon oxidation by dinitrogen trioxide $\left(\mathrm{N}_{2} \mathrm{O}_{3}\right)$ formed from the NO oxidation in the presence of oxygen [15]. Lippard and coworkers reported that a fluorescein-based $\mathrm{Cu}$ (II) complex probe can detect $\mathrm{NO}$ with the sensitivity of nanomolar concentration $[16,17]$. However, they do not react directly with $\mathrm{NO}$ molecule but monitor products of its oxidation. Furthermore, these probes cannot detect and monitor their temporal concentration but accumulated concentration in the biological systems because of their irreversibility. Wang et al. reported that inorganic QDs were coordinated iron complex for detecting NO selectively by turn-on emission with the limit of detection (LOD) of $\sim 3 \mu \mathrm{M}$ which is not enough in the biological systems [18].

A fluorescent chemo- and biosensor for NO detecting such as QD displacement without metal reduction were not reported yet. The development of fluorescent probes that are stable and significantly brighter than traditional organic fluorophores has been of considerable interest to realize biosensors with high sensitivity $[19,20]$. Semiconductor QDs are usually described as fluorophores having remarkable photostability, large absorption cross section, and tunable emission peaks [21, 22]. Furthermore, they have the better optical properties with tunable photoluminescent emissions and exceptional resistance to both photobleaching and chemical degradation.

In this work, we first report a turn-on fluorescent probe with nanomolar sensitivity to $\mathrm{NO}$ comprising CdSe/ZnS QDs coordinated with dirhodium complex. Emission from $\mathrm{CdSe} / \mathrm{ZnS}-\mathrm{QDs}$ is quenched when coordinated with the 

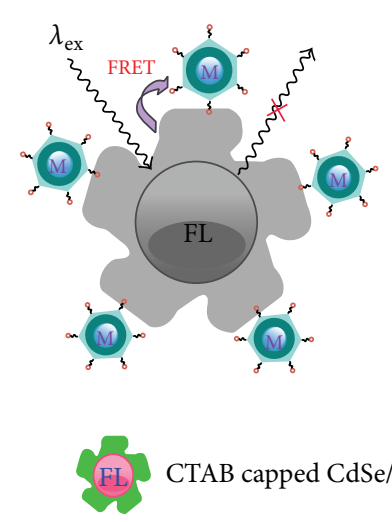

CTAB capped CdSe/ZnS-QDs

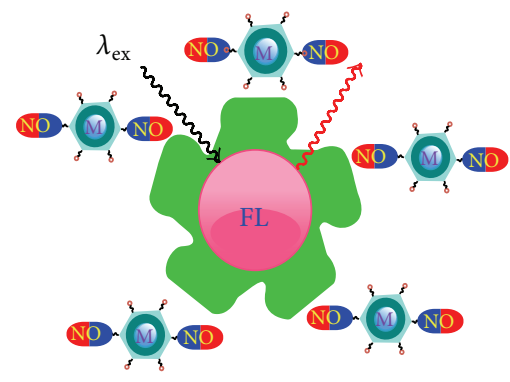

(M) Dirhodium complex

SCHEME 1

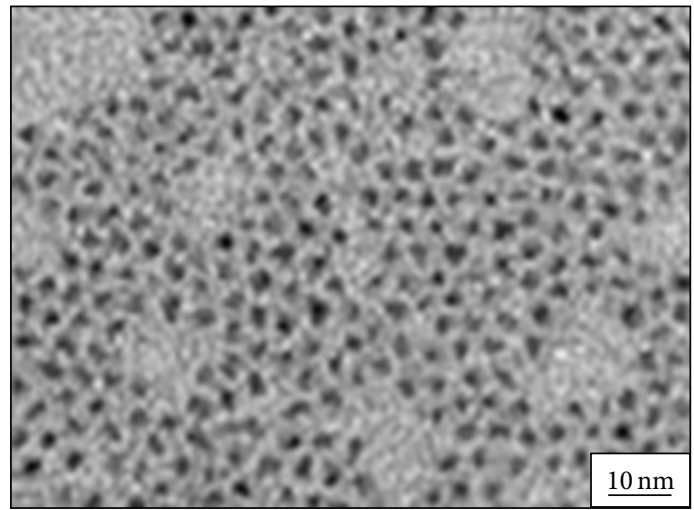

(a)

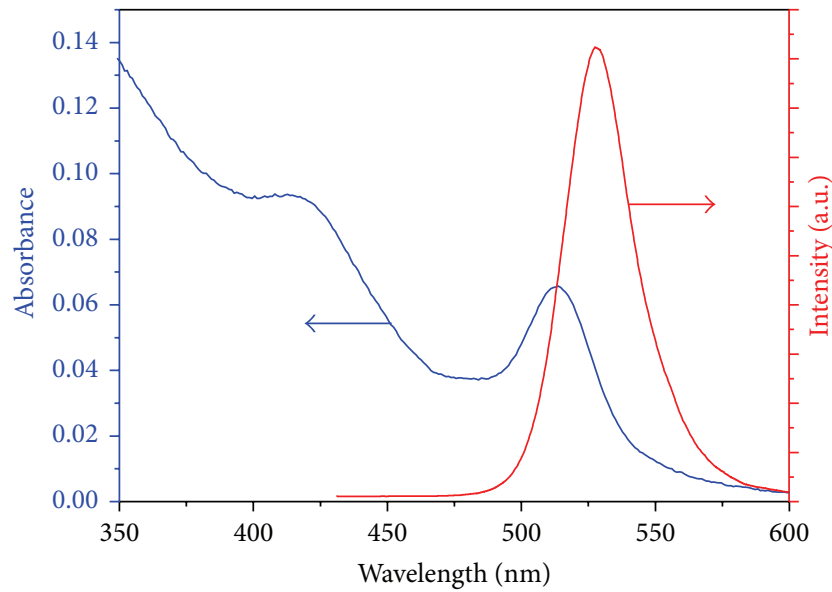

(b)

FIGURE 1: (a) FE-TEM micrographs of and (b) UV-Vis absorption and fluorescence emission spectra of CdSe/ZnS-QDs.

dirhodium complex but can be restored upon the displacement by nitric oxide as shown in Scheme 1 . This suggested mechanism should be supported by the further mechanistic and theoretical studies. Figure 1 shows (a) FE-TEM micrographs of CdSe/ZnS-QDs and (b) UV-Vis absorption and fluorescence emission spectra in this work. The CdSe/ZnSQDs were successfully obtained with about $3 \mathrm{~nm}$ diameter of spherical nanoparticles as observed in Figure 1(a). The green fluorescence emission of CdSe/ZnS-QDs was observed ca. $530 \mathrm{~nm}$ of wavelength as shown in Figure 1(b). Based on the quantum yield of Rhodamine $6 \mathrm{G}$ as a reference, the report shows that the quantum yield of CdSe reached 58\% [23]. Figure 2 shows quenching behavior of fluorescence spectra of the $30 \mathrm{nM}$ CTAB-capped CdSe/ZnS-QDs when mixed with $300 \mathrm{nM} \mathrm{Rh}_{2}(\mathrm{AcO})_{4}$ at $40^{\circ} \mathrm{C}$ in aqueous media. The $\mathrm{CdSe} / \mathrm{ZnS}$ QDs were quenched with increasing reaction time. Initially, the fluorescence of $\mathrm{CdSe} / \mathrm{ZnS}$-QDs was rapidly decreased for $30 \mathrm{~min}$ but was no longer decreased after 7 hours. Figure 3 shows the intensity change of photoluminescence spectra of the $30 \mathrm{nM}$ CdSe/ZnS-QDs containing $300 \mathrm{nM}$ dirhodium complex according to the addition amount of
DEA/NO (diethylamine NONOate, 2-(N,N-diethylamino)diazenolate-2-oxide, and diethylammonium salt). DEA/NO is a complex of diethylamine with nitric oxide used to generate a controlled release of nitric oxide in solution.

Upon adding $3000 \mathrm{nM}$ DEA/NO, the fluorescence intensity of the CdSe/ZnS-QDs containing dirhodium complex was switched on and reached its maximum immediately. As shown in Figure 3, the CdSe/ZnS-QDs containing dirhodium complex in aqueous media showed ca. $80.3 \%$ increase in relative fluorescence emission when adding to 100 equiv. of DEA/NO. In the case of 50 and 10 equiv. of DEA/NO, the relative intensity of fluorescence emission showed ca. $48.5 \%$ and $27.3 \%$ increase, respectively.

This result suggests that the probe can detect NO with nanomolar sensitivity much better than previous works. NO sensors comprising transition metal complexes coordinated with organic fluorophores were reported utilizing cobalt [24], ruthenium [25], and dirhodium complex [26]. But these systems are limited by low sensitivity $(\sim 4 \mu \mathrm{M})$ and their lack of water compatibility in the biological systems. However, we need to carry out the selectivity experiment 


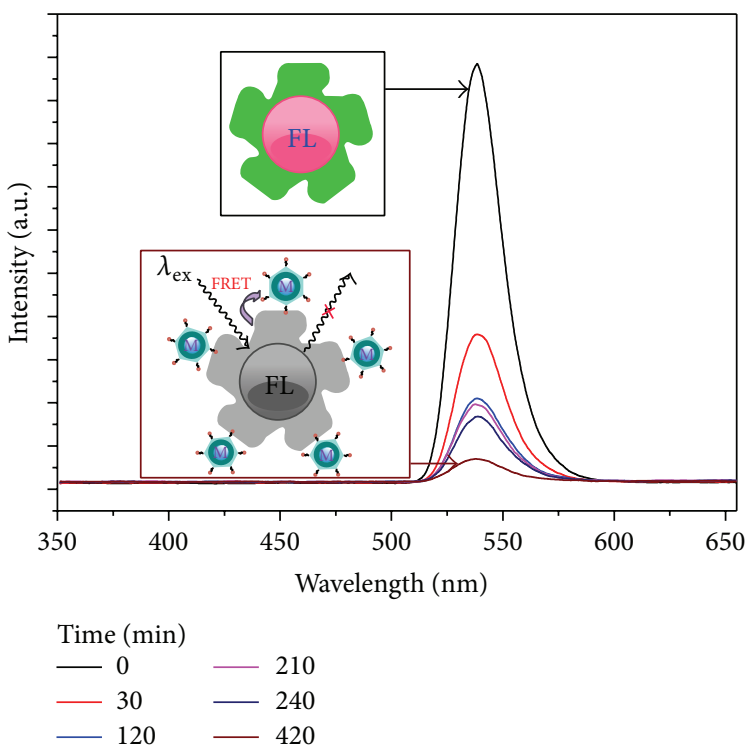

Figure 2: The intensity change of photoluminescence spectra of solutions mixed with the CTAB-capped CdSe/ZnS-QDs and dirhodium acetate as a function of the reaction time.

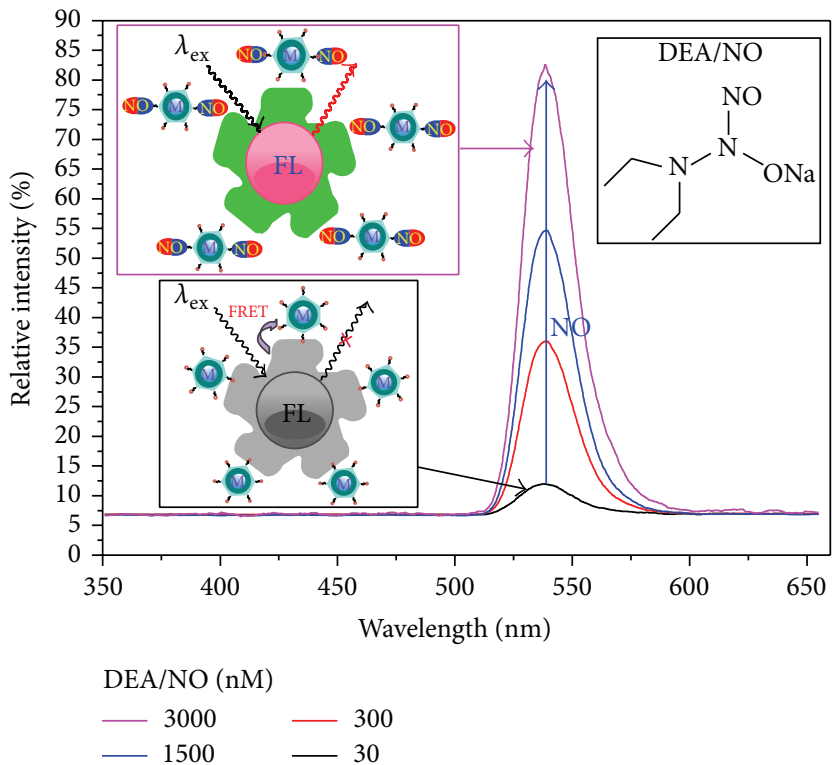

FIGURE 3: The intensity change of photoluminescence spectra of the CdSe/ZnS-QDs containing dirhodium complex as a function of the concentration of DEA/NO.

for this fluorescent probe including the dirhodium complex even though the probe consisting of densyl piperazine dye coordinated with dirhodium complex shows the excellent selectivity to NO [27]. Further studies will be performed to figure out whether the probe is interfered with other species such as $\mathrm{HOCL}, \mathrm{H}_{2} \mathrm{O}_{2}, \mathrm{tBuOOH}$, and cysteine. In order to investigate the reversibility of the probe, the process adding DEA/NO solution to CdSe/ZnS-QDs coordinated dirhodium complex was carried out twice. The ratio of QDs : dirhodium complex : DEA/NO remains the same as $1: 10: 50$. In the first step, $2 \mathrm{~mL}$ of $1500 \mathrm{nM}$ DEA/NO solution was injected into
$4 \mathrm{~mL}$ of $45 \mathrm{nM}$ CdSe/ZnS-QDs containing dirhodium complex. Then $\mathrm{N}_{2}$ in the solution was purged for $30 \mathrm{~min}$ to take NO molecule off the surface of CdSe/ZnS-QDs. After that, $2 \mathrm{~mL}$ of $1500 \mathrm{nM}$ DEA/NO solution was injected into $4 \mathrm{~mL}$ of $30 \mathrm{nM}$ CdSe/ZnS-QDs containing dirhodium complex again. As shown in Figure 4, the relative fluorescence intensity of "turn-on" state after the first and second step showed 54.2\% and $27 \%$ increase, respectively. And the relative intensity of "turn-off" state before injecting DEA/NO solution is $6.4 \%$ and $2.9 \%$, respectively. It should be noted that the ratio of "turn-on" to "turn-off" shows 8.46 and 9.3, respectively. This 

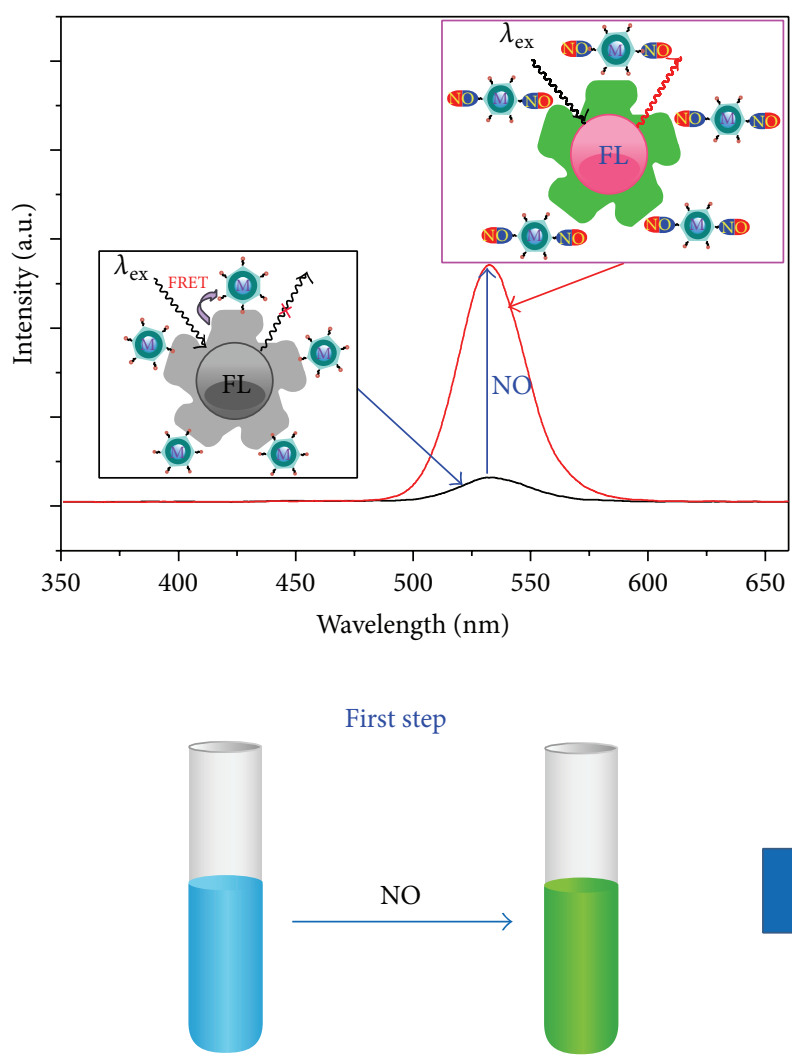
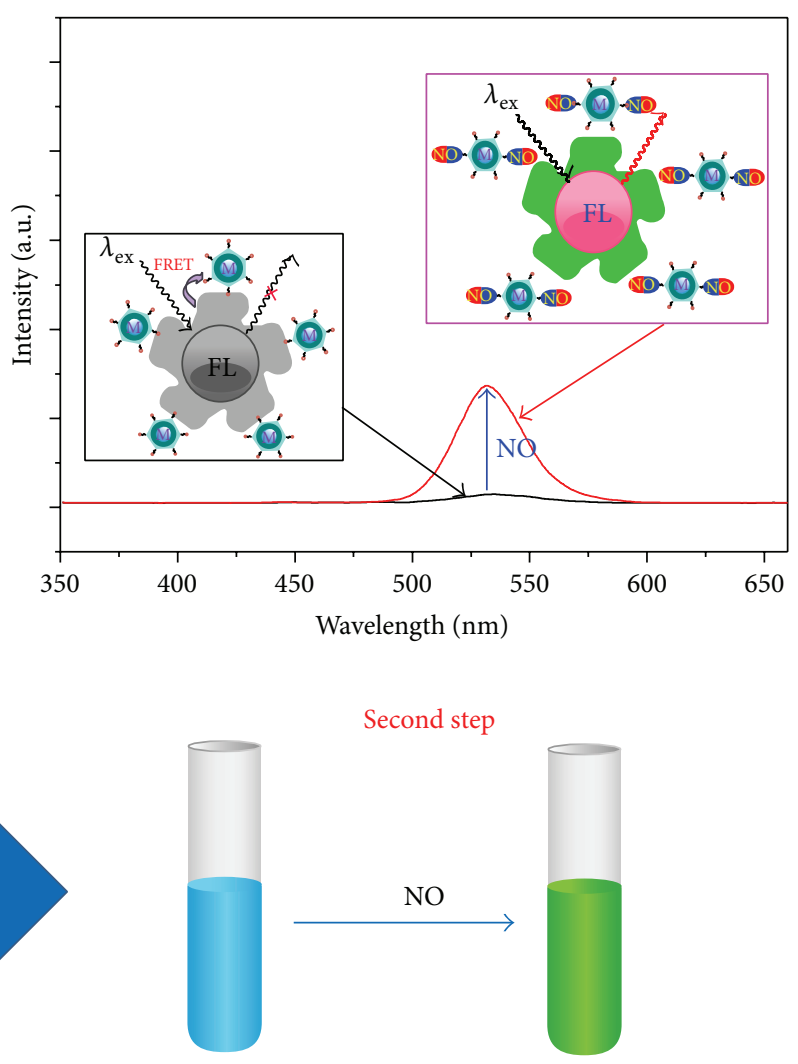

FIGURE 4: Photoluminescence spectra of the CdSe/ZnS-QDs containing dirhodium complex with repetitious addition of DEA/NO solution.

result suggests that the CdSe/ZnS-QDs nanohybrid can be used for the recyclable turn-on sensors for NO detection. This finding is very important because the probe must be reversible for monitoring the real concentration specially and temporally in the biological systems.

In summary, we first demonstrated here a "turn-on" reversible fluorescence probe with nanomolar sensitivity. Addition of DEA/NO solution to the aqueous solution of QDs nanohybrids affords a substantial increase in fluorescence intensity reversibly. The result shows that the nanohybrids turn on with nanomolar sensitivity upon the displacement of dirhodium complex by nitric oxide. These results suggest that the nanohybrids can be used for monitoring and imaging $\mathrm{NO}$ concentration directly in biological systems with a "turn-on" manner.

\section{Conflict of Interests}

The authors declare that there is no conflict of interests regarding the publication of this paper.

\section{Acknowledgments}

This work was supported by a grant from the Fundamental R\&D Program for Core Technology of Materials and a grant (no. 2012T10010005) for New and Renewable Energy of Korea Institute of Energy Technology Evaluation and Planning (KETEP) funded by the Ministry of Trade, Industry and Energy, Republic of Korea.

\section{References}

[1] L. J. Ignarro, G. M. Buga, K. S. Wood, R. E. Byrns, and G. Chaudhuri, "Endothelium-derived relaxing factor produced and released from artery and vein is nitric oxide," Proceedings of the National Academy of Sciences of the United States of America, vol. 84, no. 24, pp. 9265-9269, 1987.

[2] R. M. J. Palmer, A. G. Ferrige, and S. Moncada, "Nitric oxide release accounts for the biological activity of endotheliumderived relaxing factor," Nature, vol. 327 , no. 6122, pp. 524-526, 1987.

[3] J. Garthwaite, "Concepts of neural nitric oxide-mediated transmission," European Journal of Neuroscience, vol. 27, no. 11, pp. 2783-2802, 2008.

[4] C. Bogdan, "Nitric oxide and the immune response," Nature Immunology, vol. 2, no. 10, pp. 907-916, 2001.

[5] D. Fukumura, S. Kashiwagi, and R. K. Jain, "The role of nitric oxide in tumour progression," Nature Reviews Cancer, vol. 6, no. 7, pp. 521-534, 2006.

[6] S. Mocellin, V. Bronte, and D. Nitti, "Nitric oxide, a double edged sword in cancer biology: searching for therapeutic opportunities," Medicinal Research Reviews, vol. 27, no. 3, pp. 317-352, 2007.

[7] H. Hong, J. Sun, and W. Cai, "Multimodality imaging of nitric oxide and nitric oxide synthases," Free Radical Biology and Medicine, vol. 47, no. 6, pp. 684-698, 2009.

[8] G. Sivaraman, T. Anand, and D. Chellappa, "A fluorescence switch for the detection of nitric oxide and histidine and its application in live cell imaging," ChemPlusChem, vol. 79, no. 12, pp. 1761-1766, 2014. 
[9] H. Yu, X. Zhang, Y. Xiao, W. Zou, L. Wang, and L. Jin, “Targetable fluorescent probe for monitoring exogenous and endogenous NO in mitochondria of living cells," Analytical Chemistry, vol. 85, no. 15, pp. 7076-7084, 2013.

[10] H. Yu, L. Jin, Y. Dai, H. Li, and Y. Xiao, "From a BODIPYrhodamine scaffold to a ratiometric fluorescent probe for nitric oxide," New Journal of Chemistry, vol. 37, no. 6, pp. 1688-1691, 2013.

[11] H. Yu, Y. Xiao, and L. Jin, "A lysosome-targetable and twophoton fluorescent probe for monitoring endogenous and exogenous nitric oxide in living cells," Journal of the American Chemical Society, vol. 134, no. 42, pp. 17486-17489, 2012.

[12] G. Sivaraman, T. Anand, and D. Chellappa, "Turn-on fluorescent chemosensor for $\mathrm{Zn}$ (ii) via ring opening of rhodamine spirolactam and their live cell imaging," Analyst, vol. 137, no. 24, pp. 5881-5884, 2012.

[13] G. Sivaraman, V. Sathiyaraja, and D. Chellappa, “Turn-on fluorogenic and chromogenic detection of Fe(III) and its application in living cell imaging," Journal of Luminescence, vol. 145, pp. 480-485, 2014.

[14] G. Sivaraman and D. Chellappa, "Rhodamine based sensor for naked-eye detection and live cell imaging of fluoride ions," Journal of Materials Chemistry B, vol. 1, no. 42, pp. 5768-5772, 2013.

[15] T. Nagano and T. Yoshimura, "Bioimaging of nitric oxide," Chemical Reviews, vol. 102, no. 4, pp. 1235-1269, 2002.

[16] M. H. Lim and S. J. Lippard, "Copper complexes for fluorescence-based NO detection in aqueous solution," Journal of the American Chemical Society, vol. 127, no. 35, pp. 1217012171, 2005.

[17] M. H. Lim, D. Xu, and S. J. Lippard, "Visualization of nitric oxide in living cells by a copper-based fluorescent probe," Nature Chemical Biology, vol. 2, no. 7, pp. 375-380, 2006.

[18] S. Wang, M.-Y. Han, and D. Huang, "Nitric oxide switches on the photoluminescence of molecularly engineered quantum dots," Journal of the American Chemical Society, vol. 131, no. 33, pp. 11692-11694, 2009.

[19] M. Han, X. Gao, J. Z. Su, and S. Nie, "Quantum-dot-tagged microbeads for multiplexed optical coding of biomolecules," Nature Biotechnology, vol. 19, no. 7, pp. 631-635, 2001.

[20] Y. Chan, J. P. Zimmer, M. Stroh, J. S. Steckel, R. K. Jain, and M. G. Bawendi, "Incorporation of luminescent nanocrystals into monodisperse core-shell silica microspheres," Advanced Materials, vol. 16, no. 23-24, pp. 2092-2097, 2004.

[21] J. Yan, M. C. Estévez, J. E. Smith et al., "Dye-doped nanoparticles for bioanalysis," Nano Today, vol. 2, no. 3, pp. 44-50, 2007.

[22] X. Zhao, R. Tapec-Dytioco, and W. Tan, "Ultrasensitive DNA detection using highly fluorescent bioconjugated nanoparticles," Journal of the American Chemical Society, vol. 125, no. 38, pp. 11474-11475, 2003.

[23] D.-S. Lee, J.-C. Lee, E.-H. Koo, and J.-H. Lee, "CdSe/ZnS QD incorporated microbeads for ultra-sensitive chemo-sensor applications," Journal of the Korean Physical Society, vol. 57, no. 41, pp. 1111-1114, 2010.

[24] S. A. Hilderbrand and S. J. Lippard, "Cobalt chemistry with mixed aminotroponiminate salicylaldiminate ligands: synthesis, characterization, and nitric oxide reactivity," Inorganic Chemistry, vol. 43, no. 15, pp. 4674-4682, 2004.

[25] M. H. Lim and S. J. Lippard, "Fluorescence-based nitric oxide detection by ruthenium porphyrin fluorophore complexes," Inorganic Chemistry, vol. 43, no. 20, pp. 6366-6370, 2004.
[26] S. A. Hilderbrand, M. H. Lim, and S. J. Lippard, "Dirhodium tetracarboxylate scaffolds as reversible fluorescence based nitic oxide sensors," Journal of the American Chemical Society, vol. 126, no. 15, pp. 4972-4978, 2004.

[27] R. C. Smith, A. G. Tennyson, and S. J. Lippard, "Polymer-bound dirhodium tetracarboxylate films for fluorescent detection of nitric oxide," Inorganic Chemistry, vol. 45, no. 16, pp. 6222-6226, 2006. 

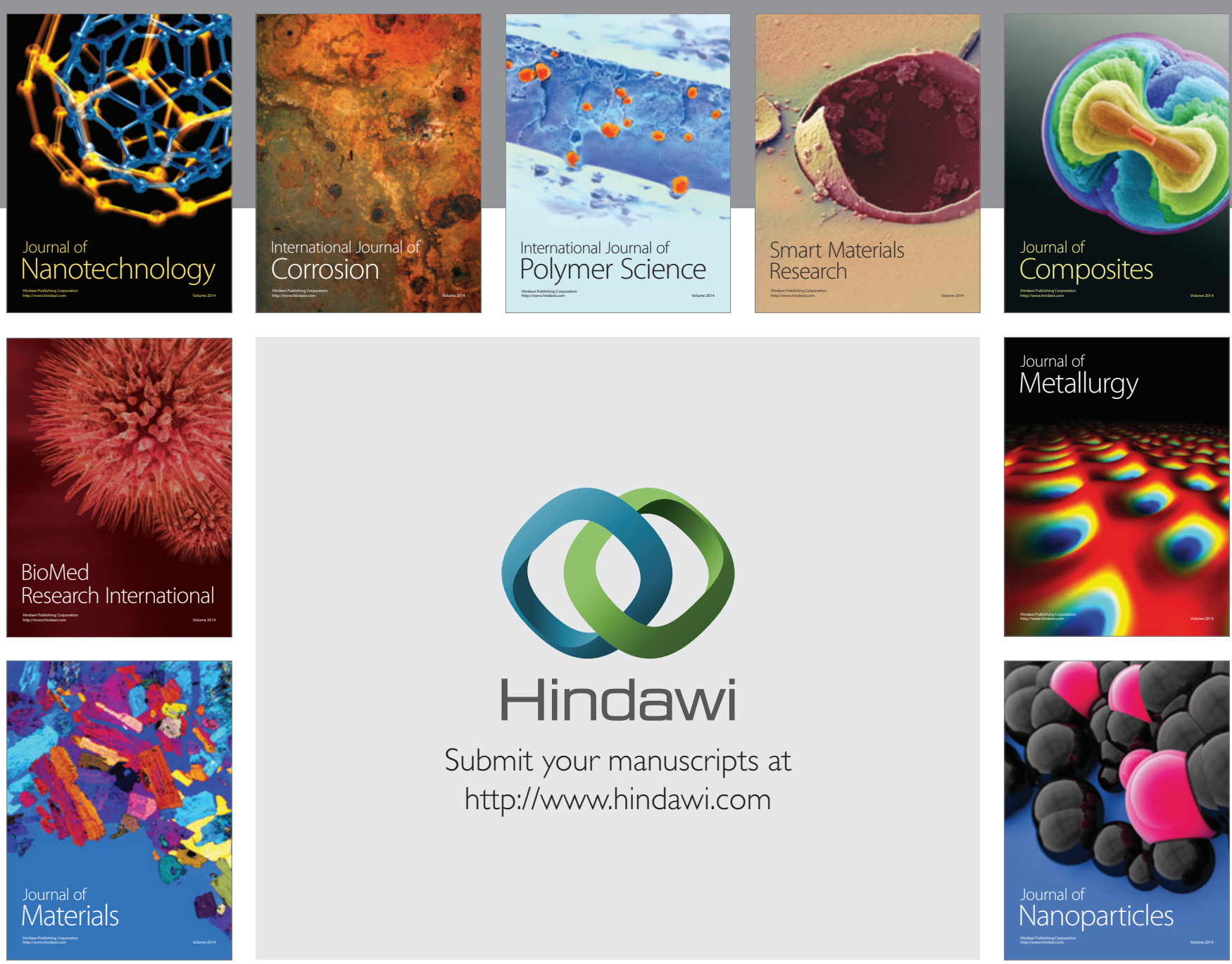

Submit your manuscripts at http://www.hindawi.com
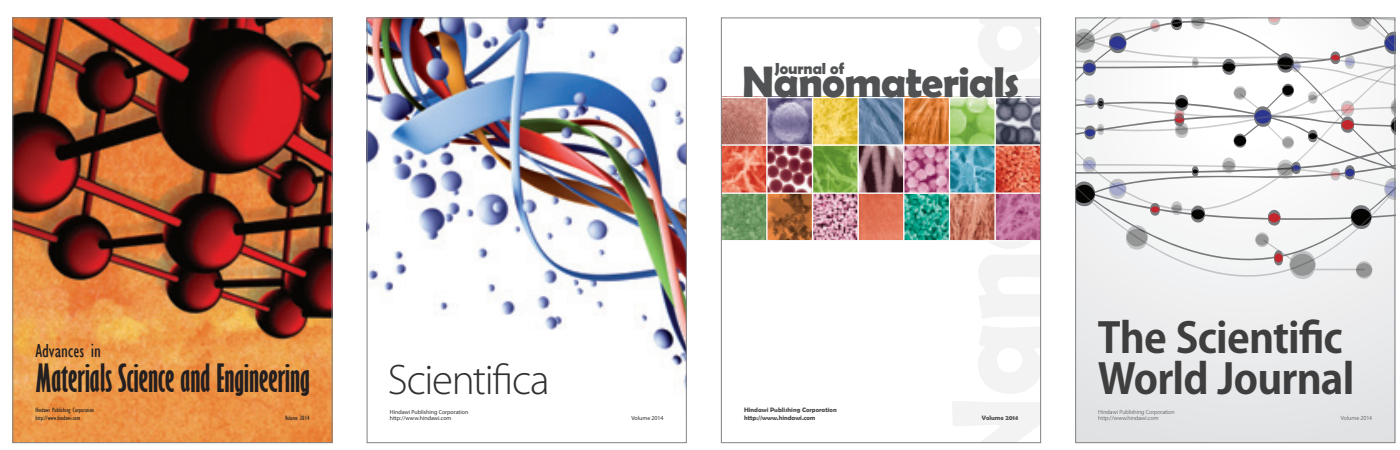

\section{The Scientific World Journal}
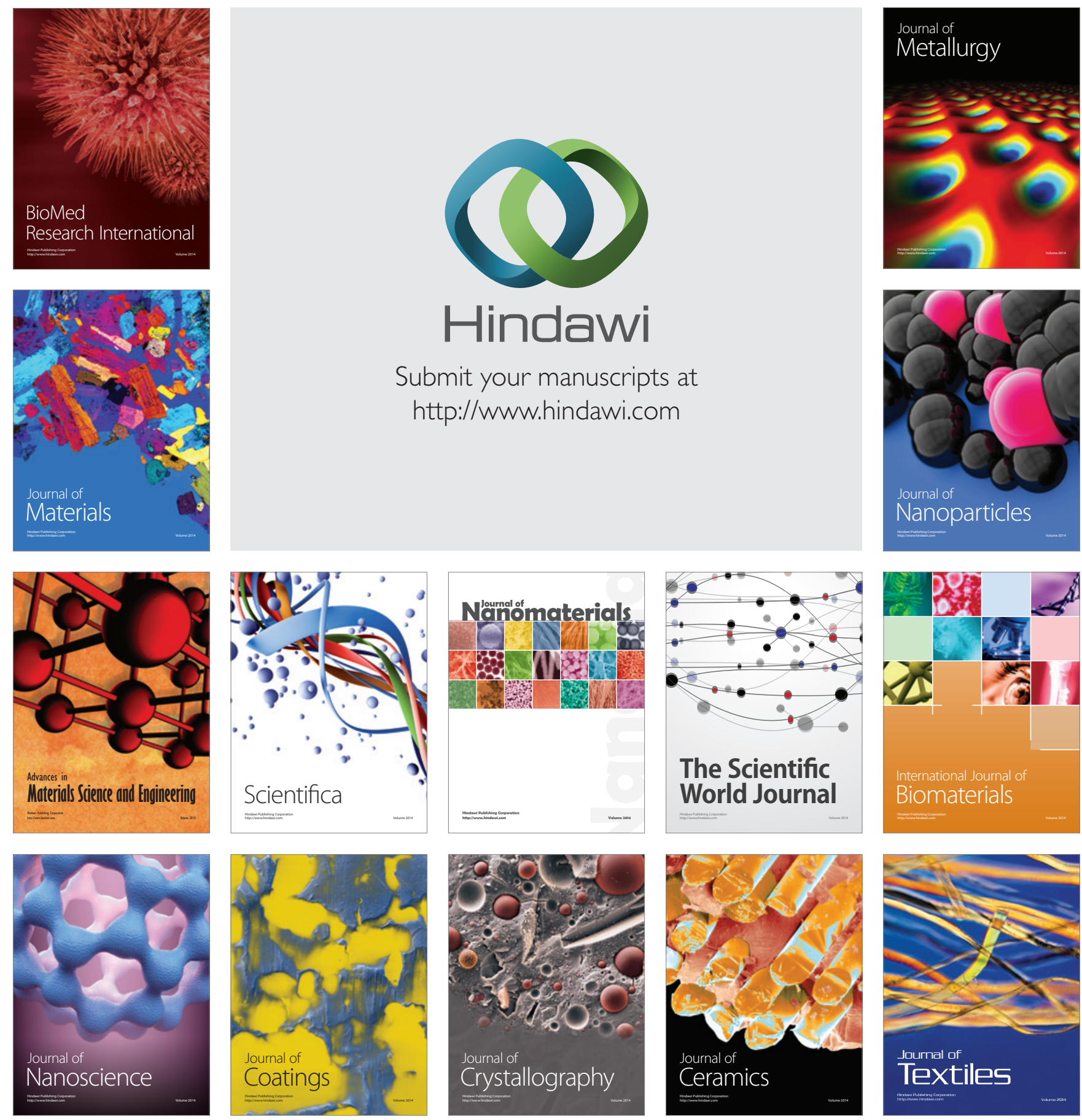